\title{
Correction to: The Comparative Effectiveness and Safety of Different Anticoagulation Strategies for Treatment of Left Atrial Appendage Thrombus in the Setting of Chronic Anticoagulation for Atrial Fibrillation or Flutter
}

\author{
Karol Kołakowski ${ }^{1}$ - Michał M. Farkowski ${ }^{1}$ Mariusz Pytkowski ${ }^{1}$. Piotr Gardziejczyk ${ }^{1}$ - Ilona Kowalik ${ }^{2}$. \\ Rafał Dąbrowski $^{2} \cdot$ Bohdan Firek $^{2} \cdot \mathrm{Krzysztof} \mathrm{Jaworski}^{2} \cdot$ Anna Klisiewicz $^{3} \cdot$ Aleksander Maciąg $^{1}$
}

Published online: 5 November 2021

(c) Springer Science+Business Media, LLC, part of Springer Nature 2021

Correction to: Cardiovascular Drugs and Therapy

https://doi.org/10.1007/s10557-021-07278-9

The original article has been corrected. Author "Piotr Gadziejczyk" should be "Piotr Gardziejczyk".

Publisher's Note Springer Nature remains neutral with regard to jurisdictional claims in published maps and institutional affiliations.

Karol Kołakowski is the first author.

Aleksander Maciąg is the senior author.

The original article can be found online at https://doi.org/10.1007/ s10557-021-07278-9.

Michał M. Farkowski

mfarkowski@gmail.com

1 II Department of Heart Arrhythmia, National Institute of Cardiology, Warsaw, Poland

2 Department of Coronary Artery Disease and Cardiac Rehabilitation, National Institute of Cardiology, Warsaw, Poland

3 Department of Congenital Heart Diseases, National Institute of Cardiology, Warsaw, Poland 